Article

\title{
An Immune Firefly Algorithm for Tracking the Maximum Power Point of PV Array under Partial Shading Conditions
}

\author{
Mingrui Zhang *, Zheyang Chen and Li Wei \\ Department of Electrical Engineering, Tongji University, Shanghai 201804, China \\ * Correspondence: zmr@tongji.edu.cn
}

Received: 17 July 2019; Accepted: 5 August 2019; Published: 9 August 2019

check for updates

\begin{abstract}
Photovoltaic (PV) string exhibits complex multiple-peak characteristics under various partial shading conditions (PSC). If the maximum power point tracking cannot be achieved quickly and accurately, it will lead to a large amount of energy loss. Therefore, it has become a hot topic to study a reliable maximum power tracking control algorithm to ensure the PV system can still output maximum power under PSC. This paper proposes an immune firefly algorithm (IFA), which utilizes vaccine data-base to shorten the convergence time, eliminates the influence of bad individuals in time by immune replenishment operation, and reduces the steady-state oscillation by the improving iteration formula. The simulations in static and dynamic environments verify that the immune firefly algorithm can track the maximum power point under various partial shading conditions. Compared with conventional firefly algorithm (FA), IFA has faster convergence speed, and can effectively restrain the oscillation of voltage and power.
\end{abstract}

Keywords: photovoltaic (PV); Firefly algorithm (FA); maximum power point tracking (MPPT); partial shading conditions (PSC)

\section{Introduction}

Ideally, the photovoltaic cells in PV array operate at the same temperature and solar irradiance. In this case, the $P-V$ curve of the PV array exhibits a single peak characteristic; the maximum power point tracking can be realized by conventional maximum power point tracking methods such as perturb-and-observe ( $\mathrm{P \& O})[1,2]$, hill climbing $(\mathrm{HC})$ [3], and incremental conductance [4]. However, under partial shading conditions, the voltage across the shaded cells will change from positive to negative, leading to the hotspot problem. To avoid this, bypass diodes are used to conduct the current generated by the unshaded cells within a module. However, this will bring another problem, that is, the $P-V$ curve of the PV array may exhibit a multiple-peak characteristic under PSC [5]. Under this circumstance, the conventional maximum power point tracking methods need a lot of time to locate the maximum power point, which leads to a large amount of energy loss.

Two approaches are commonly used to reduce or offset the shadow effect, which are implemented by software and hardware respectively. The hardware methods include circuit compensation and reconfiguration. The circuit compensation method uses an additional circuit to eliminate the multiple peaks, so even under PSC, the $P-V$ curve still shows a single peak characteristic. Therefore, the conventional MPPT methods can be used to realize MPPT [6-9]. However, the additional circuit increases the complexity of the system and cannot be flexibly adjusted to photovoltaic arrays with different structures. A reconfiguration method has been proposed in [10-12], which uses switches to reassemble each PV module in the PV array. The goal of reconfiguration is to form the PV module by photovoltaic arrays which operate under similar solar irradiance. With these methods, the complexity of the system configuration and cost are significantly increased [13]. 
The software MPPT methods can be classified into three groups. The first category is intelligent algorithms, such as, particle swarm optimization algorithm (PSO) [14-16], artificial bee colony [17], fuzzy logic control [18], chaotic search [19] and so on. The advantage of intelligent algorithms is that they accurately track maximum power point (MPP) regardless of shadow modes, $P-V$ characteristics, and PV array configurations. However, intelligent algorithms are more complex to implement. Besides, the initial points are difficult to control and have a great influence on the result of the algorithm.

The second group includes the methods that complete the MPP search by gradually narrowing the search interval, such as DIRECT method [20], and the method based on the Fibonacci technique [21]. These two methods have no significant advantage in convergence speed compared to other methods.

The third group is the improved MPPT methods based on conventional algorithms. These methods utilize the distinctive characteristics of photovoltaic systems under PSC to track MPP and can be easily implemented. In [22], a modified PSO method improves the tracking speed which is based on the comprehensive study of PV characteristics under PSC. An improved incremental conductance algorithm is proposed based on the conclusion that peaks in the $P-V$ curve usually locate at $80 \%$ of the open-circuit (OC) voltage [23-28].

In 2007, Yang developed a new intelligent algorithm called the Firefly Algorithm (FA) [29]. Sundareswaran et al. [30] implemented the FA algorithm of MPPT under PSC, and the results showed that the algorithm has better performance than PSO and P\&O. However, FA still has some defects that may bring negative impacts on the performance of MPPT. First, the location updating of fireflies is highly dependent on the excellent individuals, so the over-large distance between individuals may result in slow moving speed of low-brightness fireflies, which reduces the convergence speed of the algorithm. In addition, if the step-size coefficient $\alpha$ takes a large value, the free step-size $\alpha($ rand-1/2) in the iteration formula may result in large power and voltage oscillations, which may lead to the algorithm retreating from convergence state. However, if the step-size coefficient $\alpha$ takes a small value, it will be difficult to effectively explore the vicinity of high brightness fireflies, which leads to a long-term convergence.

To remedy the defects mentioned above, the immune firefly algorithm (IFA) utilizes the vaccine data-base to narrow the initial distribution of fireflies, therefore, most fireflies are more susceptible to the influence of excellent individuals around them. Besides, an immune replenishment operation is used to eliminate the influence of bad individuals in a timely manner. Thanks to the above improvements, the convergence speed of the algorithm has been obviously improved.

Furthermore, in order to attenuate the steady-state oscillation, the free step-size $\alpha$ (rand-1/2) is replaced by a variable step-size function, which is positively correlated with the distance between fireflies. The new iteration formula not only ensures that the low-brightness firefly can effectively detect the vicinity of the high-brightness firefly, but also weakens the steady-state oscillation of output power.

The rest of this paper is arranged as follows. The principles and implementation steps of conventional FA will be briefly introduced in Section 2. Section 3 then describes the proposed IFA method. Section 4 discusses the difference between IFA and FA and the conclusion is finally presented in Section 5 .

\section{Firefly Algorithm}

\subsection{Basic Assumptions}

Based on the characteristics that fireflies attract each other according to the brightness, FA simulates the movement of fireflies to complete the position iteration, finds the optimal position, and completes the optimization process. The conventional FA method mentioned in this paper has three idealized rules. First, all fireflies are unisex so that one firefly will be attracted to other fireflies regardless of their sex. Second, the attraction of a firefly is proportional to its brightness, for any two fireflies, one moves toward a brighter one, but the brightness decreases with distance. Finally, the brightness of a firefly is affected or determined by the objective function. 


\subsection{Terminologies of $F A$ and $P V$ System}

If FA is applied to MPPT of photovoltaic system, the terminologies of FA and PV system are shown in Table 1.

Table 1. Terminologies of Firefly Algorithm (FA) and photovoltaic (PV) system.

\begin{tabular}{cc}
\hline Firefly Algorithm & PV System \\
\hline Firefly position & Two-dimensional coordinates expressed as (Voltage, Power) \\
\hline Distance & Cartesian distance between firefly positions \\
\hline Attractiveness & An exponential function of distance \\
\hline Brightness & Power \\
\hline Brightness of the brightest firefly & Global maximum power \\
\hline
\end{tabular}

\subsection{Mathematical Expression}

Mathematically, the FA can be expressed by several equations. The attractiveness $\beta$ can be quantitatively stated as

$$
\beta=\beta_{0} e^{-\gamma r 2}
$$

where $\beta_{0}$ is the initial attractiveness at $r=0$, which is usually set to $1 . r$ is the Cartesian distance between two fireflies, and $\gamma$ is an absorption coefficient that controls the decrease of light intensity. The Cartesian distance between two fireflies $i$ and $j$ can be evaluated by the following equation:

$$
r_{i j}=\left\|x_{i}-x_{j}\right\|=\sqrt{\sum_{k=1}^{d}\left(x_{i, k}-x_{j, k}\right)^{2}}
$$

where $x_{i, k}$ and $x_{j, k}$ are the $k$ th components of the spatial coordinates of the $i$ th and $j$ th firefly. In the 2-D case, we have

$$
r_{i j}=\sqrt{\left(x_{i}-x_{j}\right)^{2}+\left(y_{i}-y_{j}\right)^{2}}
$$

If firefly $i$ is attracted to another more attractive (brighter) firefly $j$, then the movement is determined by

$$
x_{i}(t+1)=x_{i}(t)+\beta\left[x_{j}(t)-x_{i}(t)\right]+\alpha(\text { rand }-1 / 2)
$$

where $\alpha \in[0,1]$ and rand is a random number within $[0,1] . x_{i}(t)$ and $x_{j}(t)$ indicate the position of the $i$ th and $j$ th firefly at current moment, $x_{i}(t+1)$ expresses the new position after the movement.

Figure 1 summarizes the execution steps of the FA used for MPPT. First, positions of all fireflies are initialized and the number of fireflies is set to $n$, where $n$ is a positive integer. The power level of $i$ th firefly is represented by $P_{i}$. Then the $j$ th firefly's position will be updated by (4) if $P_{i}>P_{j}$. When $I=n$, rank all fireflies to obtain $P_{\max }$ which represents the maximum power of all fireflies. Finally, Formula (5) is utilized to determine whether the algorithm is convergent or not.

$$
\left|P_{\max }-P_{i}\right|<\varepsilon_{1}, i=1, \ldots, n
$$

where $\varepsilon_{1}$ is a tolerance value. 


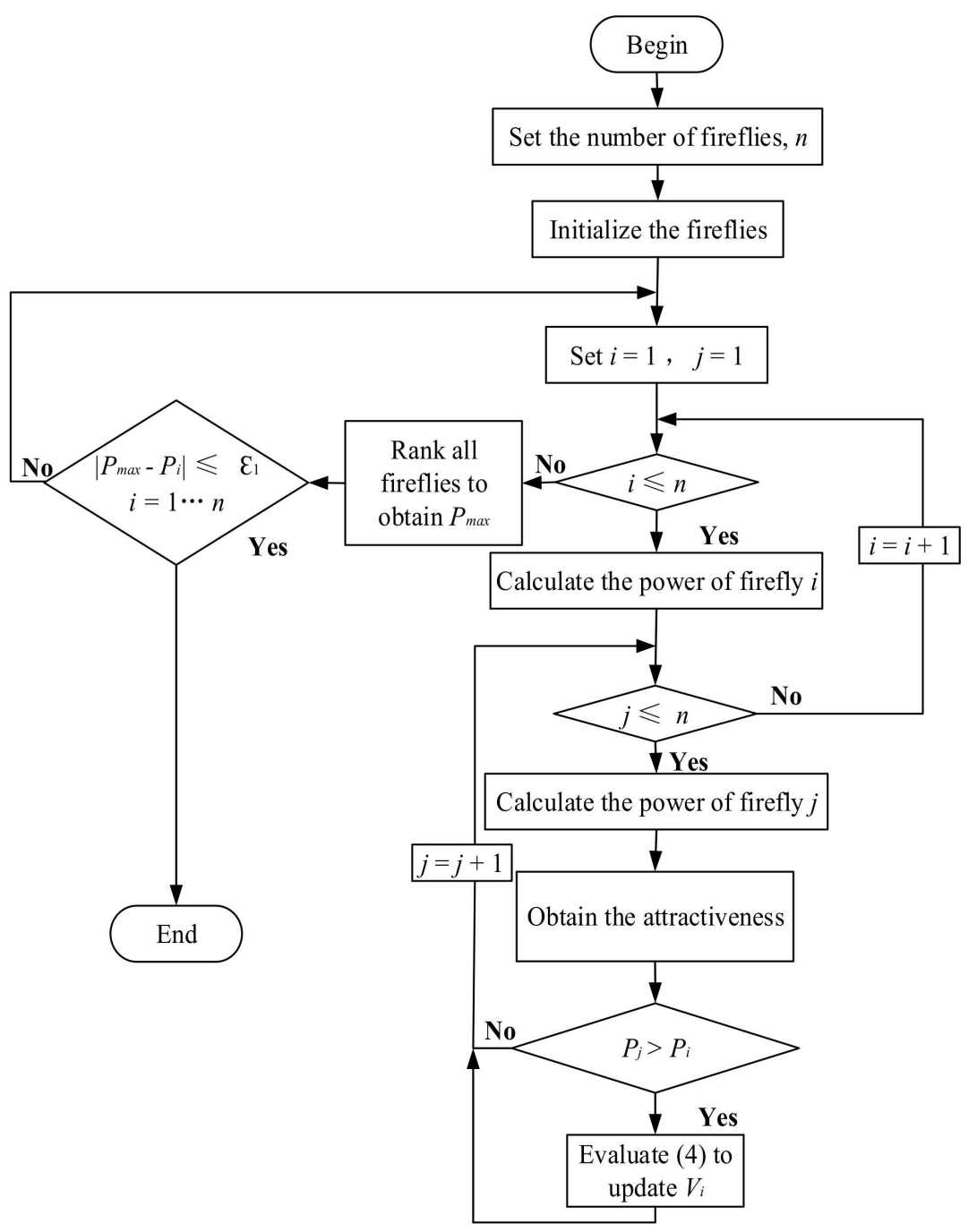

Figure 1. Flow chart of firefly algorithm (FA)

\section{Immune Firefly Algorithm}

\subsection{Vaccine Data-Base}

The working principle of the vaccine data-base is that, at regular intervals, the system performs an immune response and generates antibodies according to the data obtained from the response, thereby creating a vaccine data-base.

To set up vaccine data-base, we need to record the previously searched global maximum power point (GMPP) and obtain the voltages of these points, then group them into vaccine data-base. The steps to optimize the algorithm by vaccine data-base are as follows.

Assume that the number of previously searched GMPPs in the vaccine data-base is $m$. As shown in Figure 2, $G_{\min }$ and $G_{\max }$ represent the minimum and maximum voltage values, respectively. First of all, utilizing a Support Vector Machine (SVM) to divide the vaccine data-base into three regions based on maximizing geometrical margin, $G_{\min }$ and $G_{\max }$ are the upper and lower limits of the interval. 


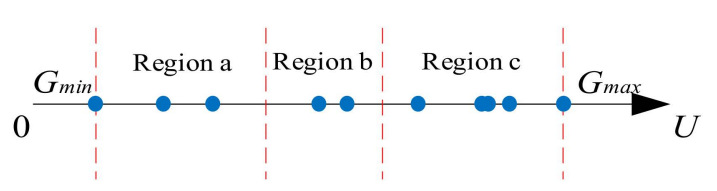

Figure 2. Using Support Vector Machine (SVM) to divide the vaccine data-base into three regions.

The second step is to count the number of historical GMPP in Region a, Region b, and Region c, and set them as $N_{\mathrm{a}}, N_{\mathrm{b}}, N_{\mathrm{c}}$ respectively. So, the initial distribution of population in Region a, Region $\mathrm{b}$, and Region c can be calculated by Formula (6).

$$
\operatorname{Minimize}\left\{\begin{array}{l}
F_{a}=n \theta \frac{N_{a}}{N_{a}+N_{b}+N_{c}} \\
F_{b}=n \theta \frac{N_{b}}{N_{a}+N_{b}+N_{c}} \\
F_{c}=n \theta_{N_{a}+N_{b}+N_{c}}
\end{array}\right.
$$

In (6), $n$ is the total number of fireflies, and $\theta$ is the constant coefficient within [0,1]. Considering that the maximum power point may appear outside of $G_{\min }-G_{\max }$, not all fireflies are determined by the vaccine data-base, only a total of $n \theta$ fireflies is determined by Formula (6). Except for $F_{\mathrm{a}}, F_{\mathrm{b}}$, and $F_{\mathrm{c}}$, the remaining number of fireflies is $n(1-\theta)$, which is randomly distributed outside the Region a, Region $\mathrm{b}$, and Region c, namely $\left[0, G_{\min }\right]$ and $\left[G_{\max }, U_{\max }\right]$, where $U_{\max }$ is the maximum voltage value that firefly individuals can get.

The appropriate value range of $\theta$ is $0.6-0.8$, if $\theta$ is larger than 0.8 , the number of fireflies distributed outside $G_{\min }-G_{\max }$ is small, so the maximum power point may be skipped. If $\theta$ is smaller than 0.6 , the role of vaccine data-base in IFA will be greatly weakened, the convergence time will also be extended.

The vaccine data-base is not invariable, it needs to be updated at the end of IFA, the new GMPP should be added into the vaccine data-base and should replace the closest historical GMPP.

\subsection{Improved Iteration Formula}

In order to reduce steady-state oscillation of FA, the uncertain variable $\alpha($ rand-1/2) in (4) is replaced, so a new iteration formula as follows will be applied to accelerate the movement of fireflies.

$$
x_{i}(t+1)=x_{i}(t)+\beta\left[x_{j}(t)-x_{i}(t)\right]+S \cdot \operatorname{rand}\{-1,1\}
$$

rand $\{-1,1\}$ expresses a value of 1 or -1 with $50 \%$ probability each, and the step-size function $S$ can be expressed as

$$
S=v\left(1-\frac{1}{e^{m}}\right) m+(\text { rand }-1 / 2) / 5
$$

where $v$ is the constant coefficient and (rand-1/2)/5 is the oscillating step size, preventing the two fireflies from getting too close, the step function is too small to effectively explore nearby intervals.

$$
m=\frac{r}{U_{\max }}
$$

In (8), $r$ can be calculated by Formula (2) and $U_{\max }$ is the maximum output voltage. As shown in Figure 3, if fireflies are far apart, the value of $S$ is large, and the firefly with low brightness can effectively explore the vicinity of the high-light fireflies, if fireflies are close together, the value of $S$ is small, make sure the steady-state oscillation within a reasonable range. Besides, the upper threshold of $S$ is set to 10 . If the calculation result of $S$ is larger than 10 , the value is set to 10 . 


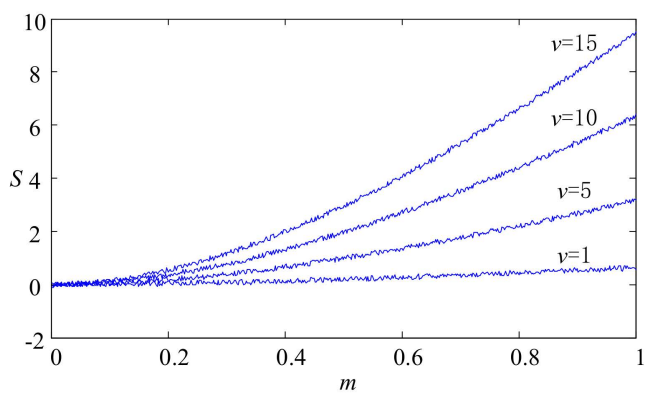

Figure 3. Image of $S$ function when $v=1,5,10,15$.

\subsection{Immune Replenishment Operation}

Notice that, if the distance between two fireflies is large, the value of $\beta$ will be extremely small, resulting in the low-light fireflies almost stay in situ during the process of running the algorithm. By carrying out the immune replenishment operation, that is eliminating inferior individuals from fireflies and replenishing new individuals, the following situation can be avoided: most fireflies are gathered in an area, a few fireflies stay in situ without obviously moving due to the long distance. The specific steps of IFA are as follows.

In IFA, after ranking all fireflies to get the $P_{\max }$, several fireflies will be replaced by randomly generated individuals in region $G_{\min }-G_{\max }$, and the replaced fireflies should satisfy the following conditions. First, the replaced fireflies have lower brightness than the rest. Second, the number of fireflies that do not satisfy Formula (5) is less than or equal to the number of replaced fireflies $\mu n, n$ is the number of all fireflies and $\mu$ is a constant coefficient. If the value of $\mu$ is too large, the speed of algorithm will be decreased and if the value of $\mu$ is too small, the immune replenishment operation will lose its effect, then the reasonable value range of $\mu$ should be $0.2-0.5$.

Figure 4 summarizes the execution steps of the IFA and the red frame indicates the differences between IFA and FA.

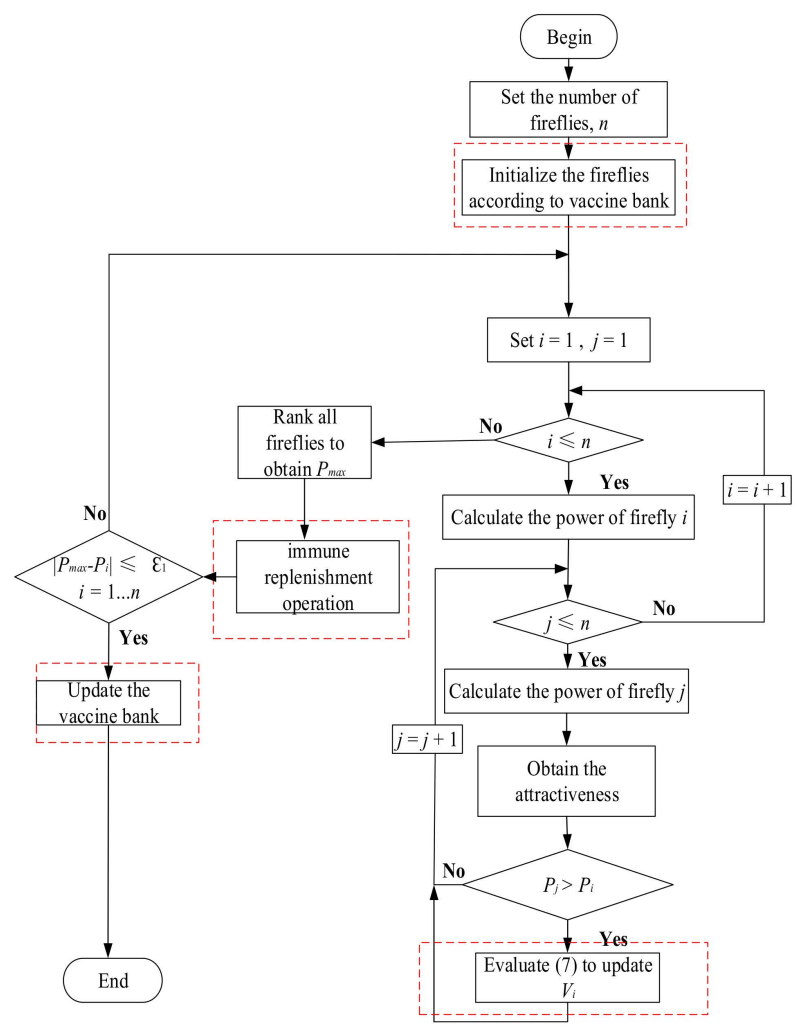

Figure 4. Flow chart of immune firefly algorithm (IFA). 


\section{Case Studies}

\subsection{Parameters}

Table 2 shows the parameter values for IFA, the peak power of PV array is $50 \mathrm{~kW}$, the open-circuit voltage is $880 \mathrm{~V}$, and the maximum power point voltage is $730 \mathrm{~V}$. Besides, the vaccine data-base contains 10 GMPPs that have been searched, namely $200.2 \mathrm{~V}, 248.5 \mathrm{~V}, 386.3 \mathrm{~V}, 522.2 \mathrm{~V}, 564.55 \mathrm{~V}, 609.7 \mathrm{~V}, 622.09 \mathrm{~V}$, $700.7 \mathrm{~V}, 730.0 \mathrm{~V}, 807.8 \mathrm{~V}$.

Table 2. Parameter setting of immune firefly algorithm (IFA) algorithm.

\begin{tabular}{cc}
\hline Parameters & Value \\
\hline$n$ & 10 \\
\hline$\gamma$ & $10^{-8}$ \\
\hline$\beta_{0}$ & 1 \\
\hline$\alpha$ & 0.5 \\
\hline$v$ & 5 \\
\hline$\theta$ & 0.6 \\
\hline$\mu$ & 0.2 \\
\hline
\end{tabular}

In Sections 4.2 and 4.3, the performance of IFA and FA algorithms in static and dynamic environments will be investigated respectively. Due to the uncertainty of irradiance and temperature, the position of the maximum power point of PV is uncertain. Therefore, this paper focuses on three different static conditions shown in Figure 5, i.e., the location of the maximum power point occurs at the left, the middle, and the right to prove that even if the maximum power point occurs at different positions, IFA can still realize MPPT.
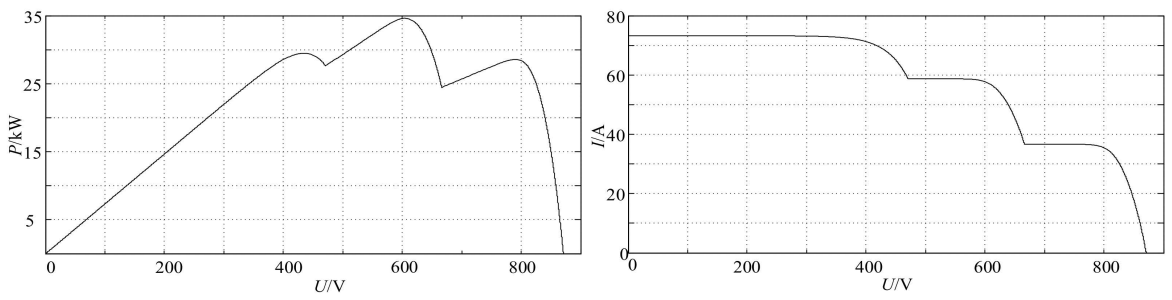

(a) GMPP occurs at middle
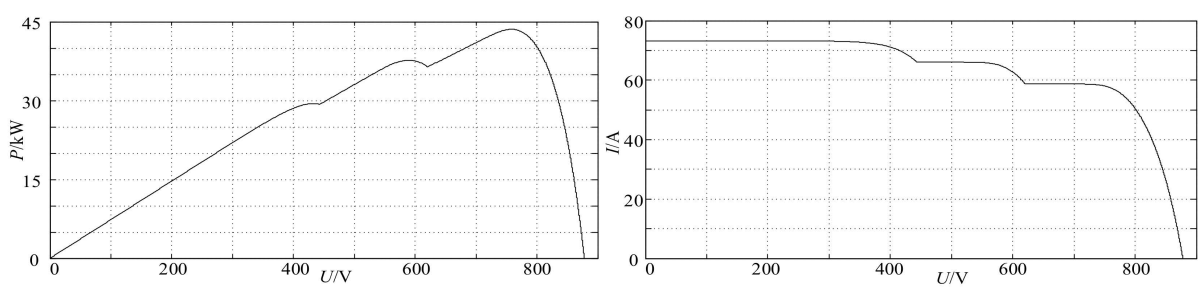

(b) GMPP occurs at right
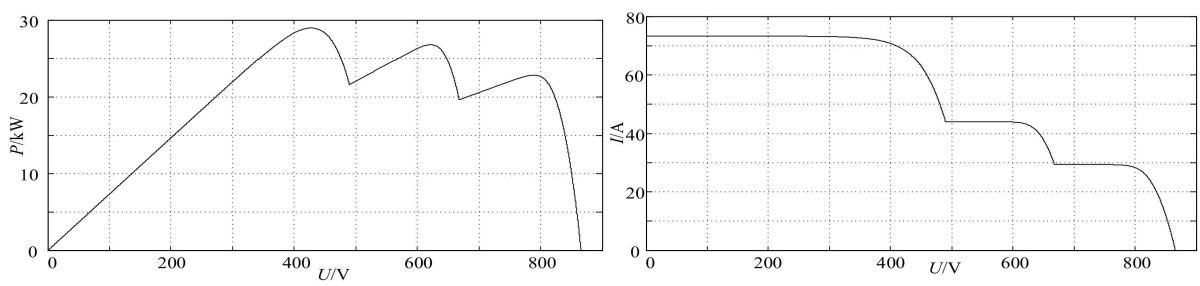

(c) GMPP occurs at left

Figure 5. Different $P-V$ curves under various shading. 


\subsection{Static Cases}

Case 1: As shown in Figure 5a, there are three LMPPs and the GMPP occurs at the middle one, the maximum power is $34,682.4 \mathrm{~W}$. Figure 6 shows the power (top plot) and voltage (bottom plot) waveforms when the IFA is employed for the MPPT. As can be seen from the voltage plot in Figure 6, IFA takes 39 steps or iterations to make the output power closely tracks the GMPP, this process takes $0.49 \mathrm{~s}$. The first ten iterations represent the initial location of fireflies. Then, each fly rotates its position according to the brightness of the other flies.

However, it takes $1.76 \mathrm{~s}$ (i.e., 149 iterations or steps) for FA to reach the GMPP. Since the proposed IFA uses the vaccine data-base to narrow the initial distribution area, moreover, immune replenishment operation ensures that every individual in the fireflies can play a role, therefore, the proposed IFA drastically reduces the convergence time.

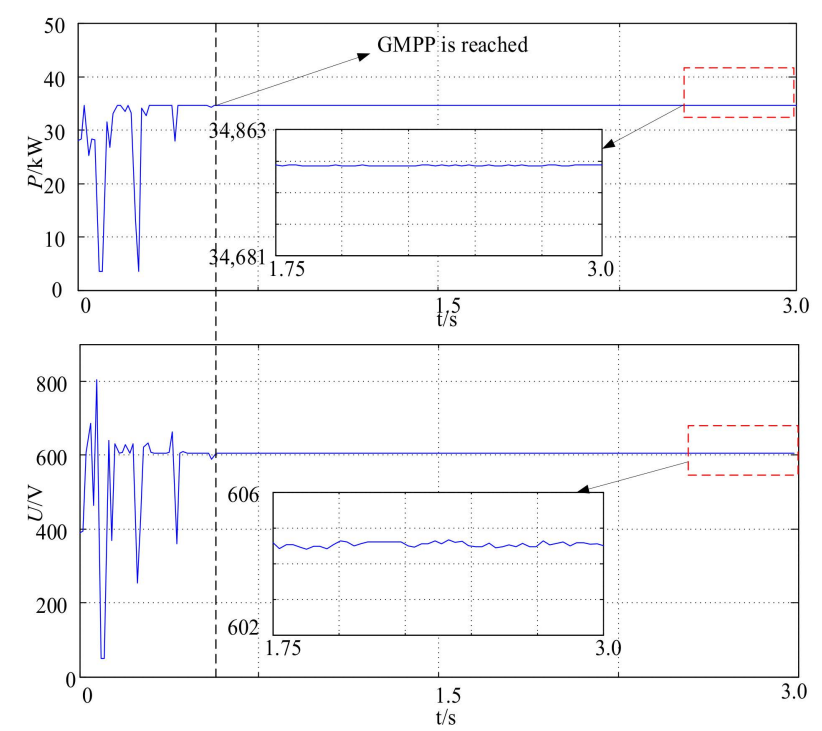

Figure 6. Voltage and power waveforms of IFA for case 1 if global maximum power point (GMPP) occurs at middle.

In addition to reducing the convergence time, IFA can also suppress the steady-state oscillation of the algorithm. As shown in Figures 6 and 7, the part shown in the red dotted frame indicates the fluctuation of output power after the convergence of the algorithm. It demonstrates that variable step-size function $S$ can effectively reduce the oscillation of output power after convergence. Note that in Case 1, GMPP was obtained at $604.5 \mathrm{~V}$, so $604.5 \mathrm{~V}$ should be added to the vaccine data-base while $609.7 \mathrm{~V}$ was removed.

Case 2: There are three LMPPs and the maximum power is $43,676.8 \mathrm{~W}$, in this case the GMPP occurs at the rightmost of the $P-V$ curve as shown in Figure $5 \mathrm{~b}$. Figure 8 shows the voltage and power waveforms when the IFA is employed. As seen from Figure 8, it takes 31 steps (i.e., $0.45 \mathrm{~s}$ ) to reach the GMPP. Figure 9 shows the voltage and power waveforms of FA. It takes 223 steps (i.e., $2.6 \mathrm{~s}$ ) to reach the GMPP. Similarly, in this case, the power oscillation in Figure 8 is slighter than that in Figure 9. 

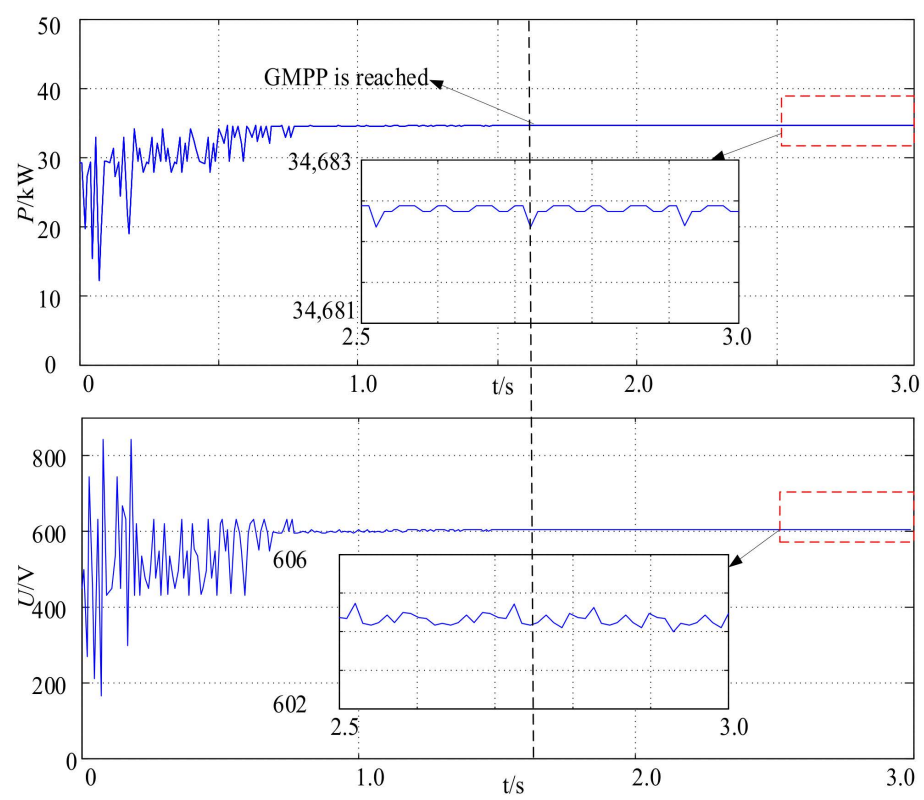

Figure 7. Voltage and power waveforms of FA for case 1 if GMPP occurs at middle.
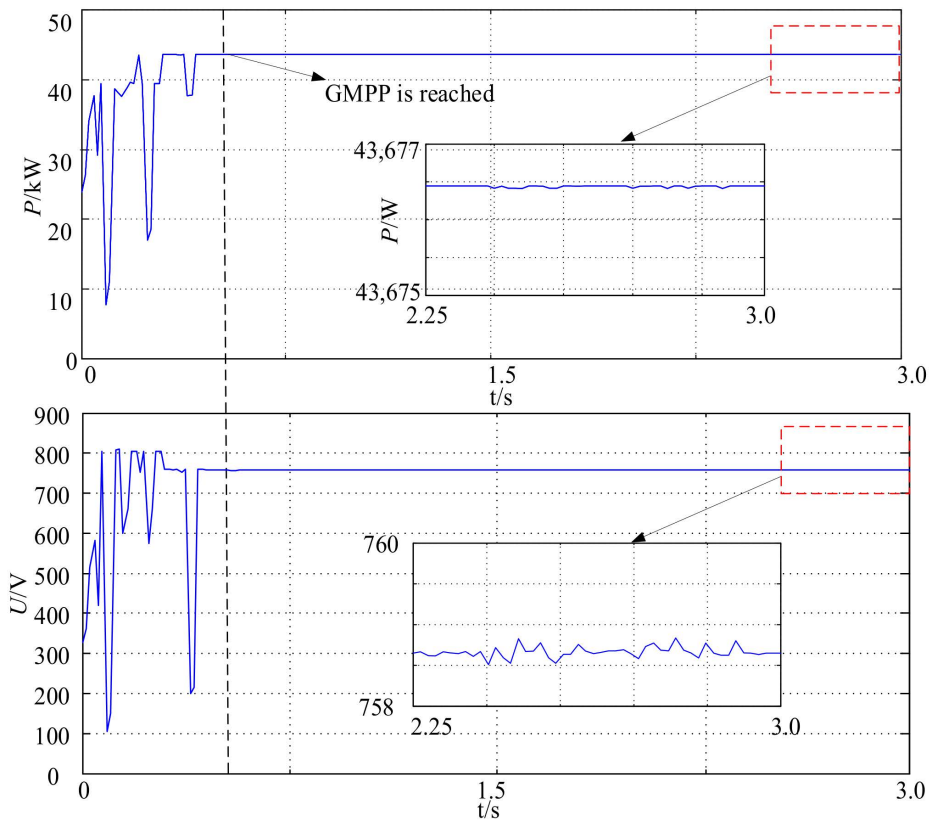

Figure 8. Voltage and power waveforms of IFA for case 2 if GMPP occurs at right. 


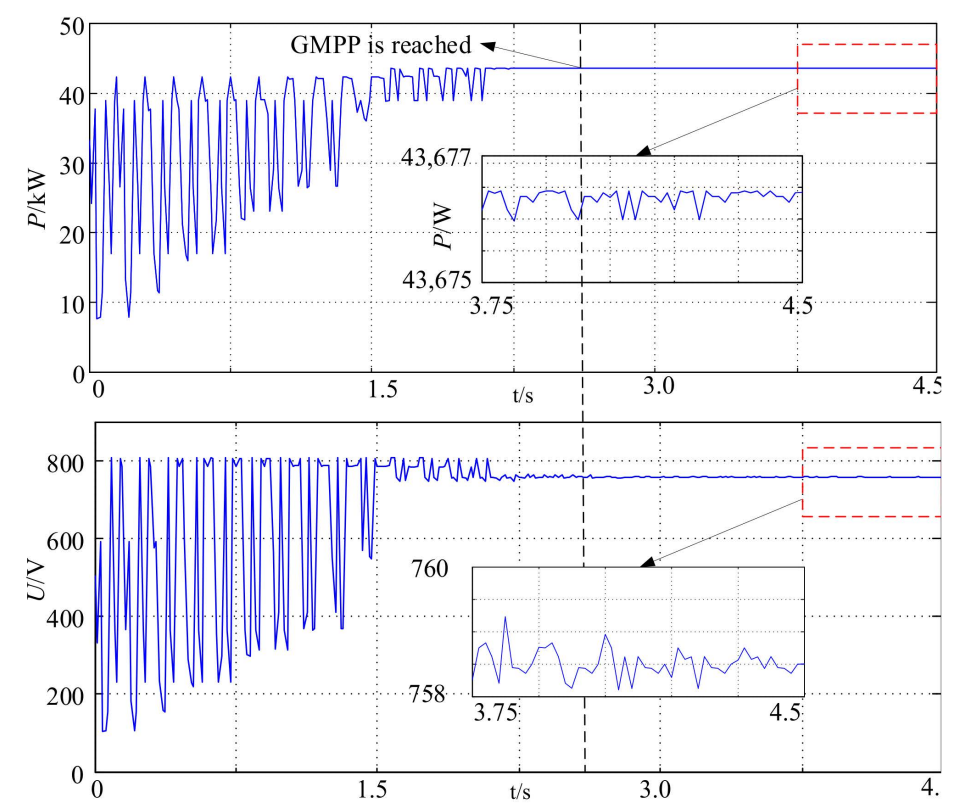

Figure 9. Voltage and power waveforms of FA for case 2 if GMPP occurs at right.

For the waveforms of Case 3 (the GMPP occurs at the leftmost on the $P-V$ curve and the maximum power is 29,031.6 W), they follow the similar trend of Case 1 and Case 2. In Case 2 and Case 3, GMPP was obtained at $758.6 \mathrm{~V}$ and $427.8 \mathrm{~V}$, respectively. So, $730.0 \mathrm{~V}$ and $386.3 \mathrm{~V}$ in the vaccine data-base should be replaced by $758.6 \mathrm{~V}$ and $427.8 \mathrm{~V}$.

For IFA and FA, the initial position of firefly is totally random, so the convergence time will be slightly different in each run. Therefore, we have run IFA and FA 10 times each under the three cases showed above and record the results in Table 3. According to the recorded data, under various shading conditions, IFA always takes less time than FA to track the GMPP.

Table 3. Convergence time of FA and IFA.

\begin{tabular}{|c|c|c|c|}
\hline Convergence Time & Case & IFA & FA \\
\hline Best & \multirow{3}{*}{1} & $0.21 \mathrm{~s}$ & $0.60 \mathrm{~s}$ \\
\hline Worst & & $0.50 \mathrm{~s}$ & $1.56 \mathrm{~s}$ \\
\hline Average & & $0.33 \mathrm{~s}$ & $0.97 \mathrm{~s}$ \\
\hline Best & \multirow{3}{*}{2} & $0.39 \mathrm{~s}$ & $0.95 \mathrm{~s}$ \\
\hline Worst & & $0.57 \mathrm{~s}$ & $1.67 \mathrm{~s}$ \\
\hline Average & & $0.45 \mathrm{~s}$ & $1.18 \mathrm{~s}$ \\
\hline Best & \multirow{3}{*}{3} & $0.27 \mathrm{~s}$ & $0.79 \mathrm{~s}$ \\
\hline Worst & & $0.38 \mathrm{~s}$ & $1.26 \mathrm{~s}$ \\
\hline Average & & $0.31 \mathrm{~s}$ & $0.96 \mathrm{~s}$ \\
\hline
\end{tabular}

Further, the average power oscillation interval after the convergence of the IFA and the FA is calculated by the Equation (10).

$$
P_{\text {osc }}=\frac{\sum_{n=1}^{N}\left(\sum_{i=1}^{k}\left(P_{\max i}-P_{\min i}\right) / k\right)}{N}
$$

Set the maximum number of iterations of the algorithm to 30, $P_{\max i}$ and $P_{\min i}$ represent the searched maximum and minimum power values in each iteration after the convergence of the algorithm. $k$ 
represents the total number of iterations executed after the convergence and $N$ is set to 10 , which means the algorithm need to be run 10 times. The calculation results are shown in Table 4 .

Table 4. Average power oscillation interval of FA and IFA.

\begin{tabular}{ccc}
\hline \multirow{2}{*}{ Case } & \multicolumn{2}{c}{$\boldsymbol{P}_{\text {osc }} / \mathbf{W}$} \\
\cline { 2 - 3 } & IFA & FA \\
\hline 1 & 0.42 & 1.07 \\
\hline 2 & 0.69 & 1.16 \\
\hline 3 & 0.45 & 1.22 \\
\hline
\end{tabular}

\subsection{Dynamic Case}

If photovoltaic arrays work in dynamic environments, it is necessary for the MPPT method to restart when the following formula is satisfied:

$$
\frac{\left|P_{\mathrm{pv}}-P_{\mathrm{pv}, \mathrm{last}}\right|}{P_{\mathrm{pv}, \text { last }}} \geq \Delta P(\%)
$$

where $P_{\text {pv,last }}$ represents the power at the GMPP of the previous operating point and $\Delta P(\%)$ is usually set to $5 \%$. [31,32].

Two scenarios must be considered for the dynamic case. In the first scenario, the shading condition changes abruptly, leading to a significant change in $P-V$ curves. The MPPT method needs to be restarted.

The second scenario is that, the environment changes continuously, such as linear decrease or increase of solar irradiance due to cloud cover and movement. The simulated changing sequence of $P-V$ curves is presented in Figure 10, indicating that the shading pattern is constantly alternated. In this case, the MPPT algorithm will not restart.

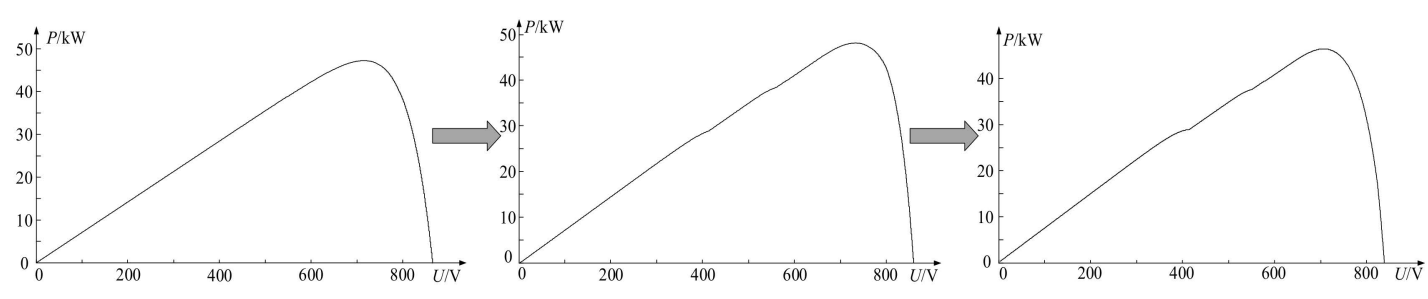

Figure 10. Power curve of IFA and FA under sudden change partial shading conditions (PSC).

Scenario 1: Figure 11 shows the tracking results for the FA and IFA of the first scenario. The $P-V$ pattern changes from Case 2 to Case 3 presented in Section 4.2 at $2 \mathrm{~s}$ and $3 \mathrm{~s}$, respectively. First, both algorithms attempt to track GMPP under uniform $P-V$ characteristics. Similar to the cases presented in Section 4.2, FA takes much longer to track GMPP. Then, after the changing of PSC, IFA still reached the GMPP faster than FA. 

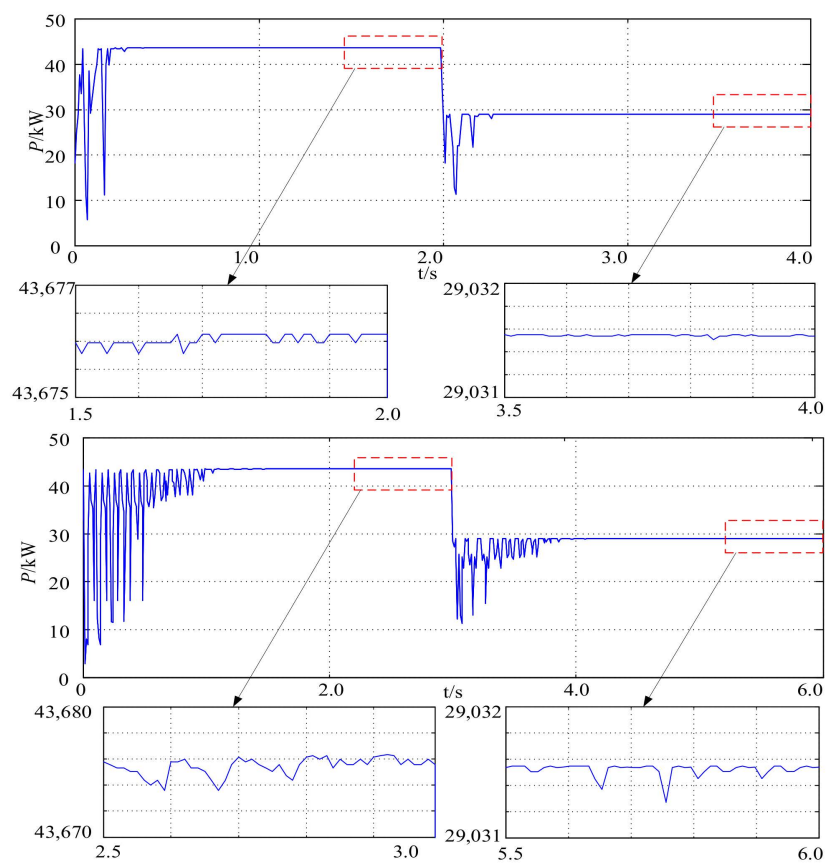

Figure 11. Top: power of the IFA for suddenly changing PSC. Bottom: power of the FA for suddenly changing PSC.

Scenario 2: In the second scenario, PSC changes gradually. It is worth noticing that for MPPT algorithms, a steady-state oscillation within reasonable numerical range is compulsory. Otherwise the new MPP will not be found when the PSC changes and the algorithm does not restart.

Figures 12 and 13 show the tracking results of IFA and FA under gradually changing PSC, maximum power changes from 49,962.3 $\mathrm{W}$ to $49,693.4 \mathrm{~W}$ at first and then changes to $49,218.2 \mathrm{~W}$. Both IFA and FA will not restart because (11) is always unsatisfied. As shown in Figures 12 and 13, both methods can successfully track GMPP. However, compared to FA, the power curve of IFA is smoother after the PSC changed, showing less power fluctuations. In addition, the FA has not accurately tracked the new GMPP, and its searched maximum power point is slightly lower than the actual GMPP.

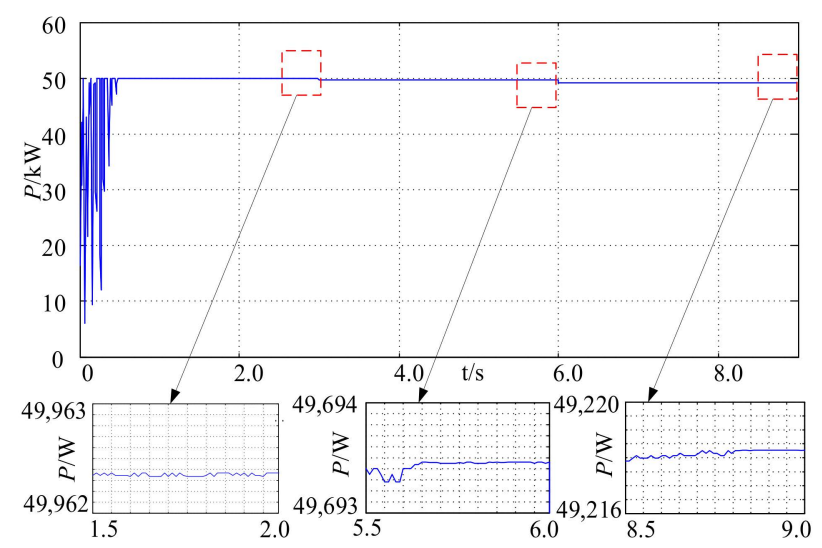

Figure 12. Power waveform of IFA under gradual change PSC. 


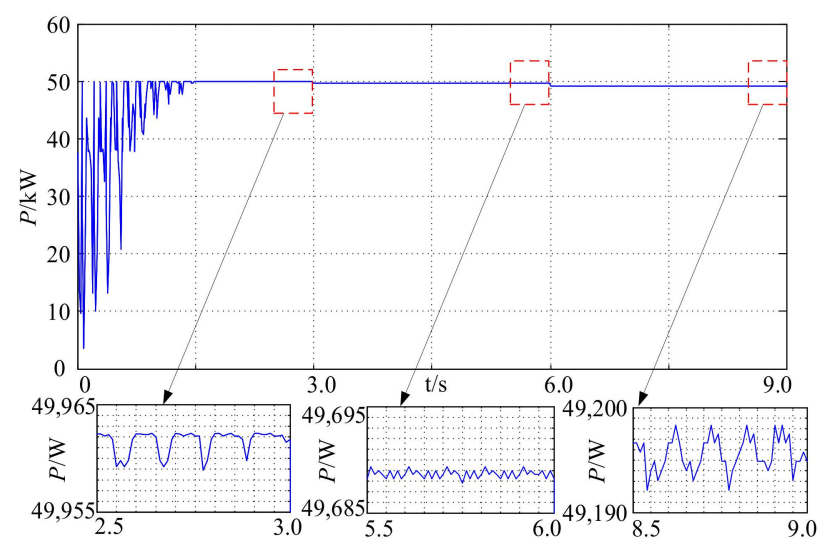

Figure 13. Power waveform of FA under gradual change PSC.

\section{Conclusions}

This paper demonstrates a new MPPT method that can be used to track GMPP when PV panels are partially obscured by clouds, snow, trees or other buildings. The proposed method modifies the iteration formula of the existing FA, adds a vaccine data-base and immune replenishment operation, so that the firefly can carry out more effective exploration and promptly eliminate the undesirable individuals in the population. Therefore, the proposed method can greatly reduce the tracking time and the steps of iterations. The simulation results in static and dynamic environments indicate that, compared with FA, the convergence time of proposed IFA is shortened by 2-3 times. Due to the short tracking time, the dynamic efficiency of IFA is generally better than FA when rapid irradiance changes occur. In the case of the sudden change in PSC, the IFA always finds the maximum power point more accurately than the FA.

Author Contributions: Conceptualization, M.Z. and L.W.; methodology, Z.C. and M.Z.; software, Z.C.; validation, Z.C. and M.Z.; formal analysis, Z.C.; investigation, L.W.; resources, L.W.; data curation, Z.C.; writing-original draft preparation, Z.C.; writing-review and editing, M.Z.

Funding: This research was funded by National Science and Technology Support Project of China, grant number 2015BAG19B02.

Conflicts of Interest: The authors declare no conflict of interest.

\section{References}

1. Jones, D.C.; Erickson, R.W. Probabilistic analysis of a generalized perturb and observe algorithm featuring robust operation in the presence of power curve traps. IEEE Trans. Power Electron. 2013, 28, 2912-2926. [CrossRef]

2. Pilawa-Podgurski, R.C.N.; Li, W.; Celanovic, I.; Perreault, D.J. Integrated CMOS energy harvesting converter with digital maximum power point tracking for a portable thermophotovoltaic power generator. IEEE J. Emerg. Sel. Top. Power Electron. 2015, 3, 1021-1035. [CrossRef]

3. Alajmi, B.N.; Ahmed, K.H.; Finney, S.J.; Williams, B.W. Fuzzylogic-control approach of a modified hill-climbing method for maximum power point in microgrid standalone photovoltaic system. IEEE Trans. Power Electron. 2011, 26, 1022-1030. [CrossRef]

4. Hsieh, G.C.; Hsieh, H.I.; Tsai, C.Y.; Wang, C.H. Photovoltaic power-increment-aided incremental-conductance MPPT with two-phased tracking. IEEE Trans. Power Electron. 2013, 28, 2895-2911. [CrossRef]

5. Spagnuolo, E.R.; Franquelo, L.G.; Ramos-Paja, C.A.; Suntio, T.; Xiao, W.M. Grid-connected photovoltaic generation plants: Components and operation. IEEE Ind. Electron. Mag. 2013, 7, 6-20.

6. Shimizu, T.; Hirakata, M.; Kamezawa, T.; Watanabe, H. Generation control circuit for photovoltaic modules. IEEE Trans. Power Electron. 2001, 16, 293-300. [CrossRef]

7. Karatepe, E.; Hiyama, T.; Boztepe, M.; Colak, M. Voltage based power compensation system for photovoltaic generation system under partially shaded insolation conditions. Energy Convers. Manag. 2008, 49, 2307-2316. [CrossRef] 
8. Sharma, P.; Agarwal, V. Maximum power extraction from a partially shaded PV array using shunt-series compensation. IEEE J. Photovolt. 2014, 4, 1128-1137. [CrossRef]

9. Sharma, P.; Argarwal, V. Exact maximum power point tracking of grid-connected partially shaded PV source using current compensation concept. IEEE Trans. Power Electron. 2014, 29, 4684-4692. [CrossRef]

10. El-Dein, M.Z.S.; Kazerani, M.; Salama, M.M.A. Optimal photovoltaic array reconfiguration to reduce partial shading losses. IEEE Trans. Sustain. Energy 2013, 4, 145-153. [CrossRef]

11. Hu, Y.; Chen, H.; Xu, R.D.; Li, R. Photovoltaic (PV) array fault diagnosis strategy based on optimal sensor placement. Proc. CSEE 2011, 31, 19-30.

12. Velasco-Quesada, G.; Guinjoan-Gispert, F.; Pique-Lopez, R.; Roman-Lumbreras, M.; Conesa-Roca, A. Electrical PV array recon-figuration strategy for energy extraction improvement in grid-connected PV systems. IEEE Trans. Ind. Electron. 2009, 56, 4319-4331. [CrossRef]

13. Koutroulis, E.; Blaabjerg, F. A new technique for tracking the global maximum power point of PV arrays operating under partialshading conditions. IEEE J. Photovolt. 2012, 2, 184-190. [CrossRef]

14. Shubhajit, S.R.; Saha, H. Maximum power point tracking of partially shaded solar photovoltaic array. Sol. Energy Mater. Sol. Cells 2010, 94, 1441-1447.

15. Liu, Y.; Huang, S.; Liang, W. A particle swarm optimization-based maximum power point tracking algorithm for PV systems operating under partially shaded conditions. IEEE Trans. Energy Convers. 2012, 27, 1027-1035. [CrossRef]

16. Ishaque, K.; Salam, Z.; Amjad, M.; Mekhilef, S. An improved particle swarm optimization (PSO)-based MPPT for PV with reduced steady-state oscillation. IEEE Trans. Power Electron. 2012, 27, 3627-3638. [CrossRef]

17. Sundareswarm, K.; Sankar, P.; Nayak, P.S.R.; Simon, S.P.; Palani, S. Enhanced energy output from a PV system under partial shaded conditions through artificial bee colony. IEEE Trans. Sustain. Energy. 2015, 6, 198-209. [CrossRef]

18. Alajmi, B.N.; Ahmed, K.H.; Finney, S.J.; Williams, B.W. A maximum power point tracking technique for partially shaded photovoltaic systems in microgrids. IEEE Trans. Ind. Electron. 2013, 60, 1596-1606. [CrossRef]

19. Zhou, L.; Chen, Y.; Guo, K.; Jia, F. New approach for MPPT control of photovoltaic system with mutative-scale dual-carrier chaotic search. IEEE Trans. Power Electron. 2011, 26, 1038-1048. [CrossRef]

20. Nguyen, T.L.; Low, K.S. A global maximum power point tracking scheme employing DIRECT search algorithm for photovoltaic systems. IEEE Trans. Ind. Electron. 2010, 57, 3456-3467. [CrossRef]

21. Ahmed, N.A.; Miyatake, M. A novel maximum power point tracking for photovoltaic applications under partially shaded insolation conditions. Electr. Power Syst. Res. 2008, 78, 777-784. [CrossRef]

22. Ishaque, K.; Salam, Z. A deterministic particle swarm optimization maximum power point tracker for photovoltaic system under partial shading condition. IEEE Trans. Ind. Electron. 2013, 60, 3195-3206. [CrossRef]

23. Patel, H.; Agarwal, V. Maximum power point tracking scheme for PV systems operating under partially shaded conditions. IEEE Trans. Ind. Electron. 2008, 55, 1689-1698. [CrossRef]

24. Tey, K.S.; Mekhilef, S. Modified incremental conductance algorithm for photovoltaic system under partial shading conditions and load variation. IEEE Trans. Ind. Electron. 2014, 61, 5384-5392.

25. Tey, K.S.; Mekhilef, S. A fast-converging MPPT technique for photovoltaic system under fast-varying solar irradiation and load resistance. IEEE Trans. Ind. Inform. 2014, 11, 176-186.

26. Tey, K.S.; Mekhilef, S. Modified incremental conductance MPPT algorithm to mitigate inaccurate responses under fast-changing solar irradiation. Sol. Energy 2014, 101, 333-342. [CrossRef]

27. Tey, K.S.; Mekhilef, S.; Safari, A. Simple and low cost incremental conductance maximum power point tracking using buck-boost converter. J. Renew. Sustain. Energy 2013, 5, 023106.

28. Seyedmahmoudian, M.; Mekhilef, S.; Rahmani, R.; Yusof, R.; Renani, E.T. Analytical modeling of partially shaded photovoltaic systems. Energies 2013, 6, 128-144. [CrossRef]

29. Yang, X.-S. Nature-Inspired Metaheuristic Algorithms; Luniver Press: Cambridge, UK, 2008.

30. Sundareswaran, K.; Peddapati, S.; Palani, S. MPPT of PV systems under partial shaded conditions through a colony of flashing fireflies. IEEE Trans. Energy Convers. 2014, 29, 463-472. 
31. Femia, N.; Petrone, G.; Spagnuolo, G.; Vitell, M. Optimization of perturb and observe maximum power point tracking method. IEEE Trans. Power Electron. 2005, 20, 963-973. [CrossRef]

32. Teshome, D.F.; Lee, C.H.; Lin, Y.W.; Lian, K.L. A Modified Firefly Algorithm for Photovoltaic Maximum Power Point Tracking Control Under Partial Shading. IEEE J. Emerg. Sel. Top. Power Electron. 2017, 5, 661-671. [CrossRef] 